\title{
SENI TRADISI DI INDONESIA DAN FENOMENA HARAM-HALAL
}

Sutiyono

FBS, Universitas Negeri Yogyakart

Email: sutiyono_63@yahoo.com

HP. 08562875090

\section{Abstrak}

Tulisan ini bertujuan untuk mengetahui posisi seni tradisi di Indonesia kaitanya dengan fonomena sosial di masyarakat yang dianggap haram dan halal. Tulisan ini mengeksplorasi posisi beberapa seni tradisi di antaranya seni slawatan yang masih hidup di masyarakat, terutama di pedesaan. Seni tradisi mampu membentuk ikatan silaturahmi, bahkan ada di antaranya yang dapat merubah akhlak seseorang dari buruk menjadi baik. Akan tetapi, seni tradisi sekarang menghadapi justifikasi dari kelompok sosial keagamaan yang memberikan persepsi atas kesenian tersebut, yakni ada yang menganggap haram dan ada pula yang menganggap halal.

Kata kunci: seni tradisi, haram-halal

\section{SENI TRADISI DI INDONESIA DAN FEOMENA HARAM-HALAL}

\section{Abstract}

This study aims to find out the position of tradition art in Indonesia related to the social phenomenon of halal-haram in the society. This study also explores the position of some tradition art such as slawatan, which still exists especially in the rural society. The tradition art is able to create a bond among the people and it can also change the bad behavior into good. However, today tradition art has to deal with the the questions given by religious communities on how to justify this kind of art since the religious communities have given their own perception on this matter by claiming that tradition art is permitted or forbidden.

Key words: tradition art, the phenomenon of halal-haram 


\section{PENDAHULUAN}

Fakta sosial yang berkembang dalam genre seni Islami yang bernama slawatan menyebutkan adanya proses penyadaran yang dialami seorang pemain masuk menjadi pemain slawatan Jawa bernama larasmadya, yaitu sebuah kesenian musik tradisonal yang dimainkan oleh sekitar 30 orang pria, mengumandangkan syair-syair sholawat Nabi dan doa-doa, disajikan pada malam hari dengan menggunakan instrumen musik rebana dan kedhang Jawa.

Ketika rajin menghadiri latihan dan pentas seni slawatan larasmadya, seseorang yang berlatar belakang sebagai pemain judi itu selalu menghayati syairsyair kesenian tersebut yang mengandung nuansa Illahi. Maka tidak begitu lama mengalirlah mata air sang pemain judi. Air mata itu kemudian membasahi seluruh tulang-tulang dan menggenangi panca indra, terutama indra ke-6 yaitu rasa. Dar rasa yang kemudian bergerak secara perlahan-lahan menyentuh sebuah organ spiritual manusia, yaitu hati. Di sinilah proses transfer dan internalisasi nilai-nilai sholawat lewat saluran estetik telah memetik area jiwa sang pemain. Akhlak yang tadinya gelap gulita sebelum menjadi pemain slawatan larasmadya, kini telah berubah menjadi terang benderang dan bersih berwarna putih. Kesukaan bermain judi telah ditinggalkan, dan sekarang rajin melaksanakan sembahyang lima waktu, bahkan menjadi donorer dalam berbagai aktivitas pengajian di kampungnya (Sutiyono, 1999: 203-204). Demikian hal ini dinyatakan oleh salah seorang pemain senior slawatan larasmadya di sebuah desa wilayah Kabupaten Sleman, Propinsi Daerah Istimewa Yogyakarta, yang menyatakan bahwa kesenian tersebut antara lain dipergunakan untuk njala (menjaring) warga di desanya yang memiliki akhlak tidak agamis

Seperti biasanya di kampung-kampung, dakwah Islam dilakukan dengan acara pengajian secara formal. Seorang dai berbicara dengan bahasa pilihan yang telah disiapkan sebelumnya, dan ketika naik mimbar ia biasa dengan penjelasan dakwah yang amat dakik-dakik (over penjelasan), yang berakibat para peserta (jama'ah) pengajian yang didakwahi malah menjadi bingung. Dalam kasus komunitas kesenian larasmadya di atas, terdapat salah seorang pemain yang menjadi sadar perilakunya ke arah yang lebih positif, disebabkan faktor dakwah natural dan kultural dari kesenian tersebut yang mampu menembus hati para pemainnya, meskipun prosesnya perlahan-lahan. Proses penyadaran itu, dalam pandangan Peter L. Berger dan Thomas Luckmann (1994), disinyalir sebagai proses dialektika antara diri (the self) dengan dunia sosio-kultural (structure). Dialektika berlangsung dalam suatu proses dengan tiga momen silmutan sebagai berikut. Pertama, eksternalisasi, yaitu penyesuaian diri dengan dunia sosiokultural sebagai produk manusia. Proses ini merupakan berlangsungnya konstruksi dan penciptaan realitas sosial oleh manusia yang sifatnya belum final, dan oleh karenanya manusia perlu menciptakan suatu 'dunia' agar menjadikan dirinya menjadi lengkap dan final. Kedua, objektivasi, yaitu interaksi sosial dalam dunia intersubjektif yang dilembagakan atau mengalami proses institusionalisasi. Proses ini adalah momen diterimanya realitas sosial hasil konstruksi manusia itu atau pendukung melalui proses kreatifitas berkeseniannya. Sebagaimana pernah terjadi dalam sebuah komunitas kesenian di pedesaan, terdapat seorang penjudi kelas berat yang menjadi anggota kelompok kesenian tersebut. Kemudian ia sebagai sebuah kenyataan yang bersifat objektif. Ketiga, internalisasi, yaitu individu mengidentifikasi diri dengan lembaga-lembaga sosial yang menjadi anggotanya. Proses ini merupakan diserapnya kenyataan objektif itu ke dalam diri individu menjadi sebuah kenyataan yang subjektif.

Pengalaman empiris yang telah dilakukan para pemain slawatan larasmadya di pedesaan itu juga memetik banyak keuntungan dakwah, antara lain jumlah kelompok (komunitas) paguyuban selalu bertambah setiap tahunnya. Kebetulan terbentuknya sebuah kelompok seni slawatan larasmadya biasanya diikuti oleh orang-orang abangan. Hal ini merupakan kesempatan bagi para pendakwah untuk menanamkan ajaran Islam lewat pembinaan seni slawatan larasmadya. Dengan tujuan dakwah itulah, para pendakwah yang berasal dari sebuah kelompok seni slawatan larasmadya menyebarkan (membina) materi slawatan larasmadya ke suatu kelompok masyarakat dusun. Para pembina itu (biasanya 4 sampai 6 orang) mengendarai sepeda/motor menuju ke suatu dusun, dengan keperluan membina slawatan larasmadya.

Adapun jangkauan pembinaan, tergantung jauh dan dekatnya wilayah dusun yang akan dibina. Ada yang 1 kilometer, tetapi ada pula yang 2, 3, 6, 7, 10, 15 , bahkan 25 kilometer. Perjalanan para pendakwah menuju sebuah dusun yang akan dibina ini dilakukan setelah sembahyang Isya, dan sampai di tempat tujuan sekitar jam 20.00. Kadang-kadang di tengah perjalanan harus rela diguyur gerimis, atau kadang-kadang hujan lebat. Bahkan dalam riwayatnya, ketika belum ada listrik di pedesaan (dan kebetulan sedang tidak ada terang bulan) para pendakwah harus membawa obor

Bila dusun yang dibina belum mempunyai alat musik, maka para pendakwah itu membawakan alat musik dari rumah. Mereka melakukan pembinaan larasmadya seminggu/duaminggu sekali selama setahun. Lantas berapa honor setiap pendakwah ini? Honornya, menurut pengakuan mereka adalah tambah sedulur, tambah srawung (memperluas persaudaraan), atau memperkokoh ikatan Ukuwah Islamiyah. Jadi, slawatan larasmadya bukan jenis seni pertunjukan komersial seperti wayang kulit, kethoprak, campursari yang menuntut bayaran sekian juta rupiah. Setiap pemain yang ikut andil pentas dalam suatu peristiwa hajatan, tidak menerima upah sepeser pun. Tidak ada istilah job ataupun kontrak. Para pemain larasmadya setiap waktu siap diundang pentas ke mana saja. Mereka toleran kepada masyarakat desa yang dibina (Irfani, 2013: 8). Kesempatan pentas dianggap oleh pemain sebagai kesempatan dakwah dan memperluas pergaulan masyarakat. Di sinilah ikatan silaturahmi antar pemain, antar kelompok, antar dusun menjadi sangat kuat. Akibatnya silaturahmi ini tidak hanya terbatas pada lingkup berkeseniannya saja, tetapi juga sampai pada dimensi sosial. Sebagai bukti, kalau ada kematian, antara pemain larasmadya saling memberi tahu, untuk kemudian melakukan takziah atau mengunjungi keluarga yang ditinggal mati, 
meskipun kadang-kadang tempatnya cukup jauh. Dimensi sosial ini juga berlaku jika terdapat saudara sakit, atau punya kerja (perhelatan). Melalui peristiwa ini, interaksi pemain slawatan larasmadya baik di dalam paguyubannya sendir maupun antar paguyuban saling menunjukkan simpati. Dengan demikian, dapa dinyatakan bahwa ikatan berkesenian mempengaruhi ikatan sosial. Mereka melakukan ini semua, karena dilandasi tendensi dakwah berdasarkan semangat ibadah dan keikhlasan.

Alangkah indahnya kehidupan mereka di pedesaan itu. Sungguh, bila kita renungkan nilai-nilai moral dan religius yang dibawa para pendakwah itu merupakan social capital (modal sosial) bangsa yang tak ternilai harganya. Bandingkan para pendakwah slawatan larasmadya itu dengan para dai, mubaligh, kyai sekarang ini yang bisa memasang tarif ratusan ribu hingga jutaan rupiah dalam setiap forum pengajian. Ketiga subjek yang disebutkan terakhir ini sudah terbius oleh era modernitas yang materialistik. Hal inil merupakan sebuah sosok kesenian rakyat yang mampu berdakwah untuk masyarakat di sekitarnya tanpa diwarnai tendensi komersialitas. Yang menjadi masalah dalam seni slawatan larasmadya tersebut adalah ia termasuk seni tradisi di Indonesia tetapi terselimuti oleh fenomena haram dan halal.

\section{FENOMENA HARAM-HALAL}

Fakta sosial menyebutkan bahwa terdapat kelompok umat Islam yang selama ini menolak hadirnya kesenian, artinya menganggap kesenian itu haram. Namun demikian kelompok umat Islam yang lain menerima kehadiran kesenian, bahkan kesenian itu juga digunakan sebagai bagian ritual untuk menjalankan ibadah (Nasr, 1994). Sampai sekarang tidak diketahui kapan kontroversi persepsi masyarakat Islam terhadap kesenian muncul ke permukaan. Kemungkinan besar, soal kontroversi persepsi tersebut sudah ada sejak zaman Nabi Muhammad SAW. Lantas menjadi wewenang siapa untuk menuntaskan persoalan kontroversi persepsi itu? Tampaknya, zamanlah yang akan menjawab persoalan perbedaan persepsi tersebut. Padahal persoalan ini kadang-kadang dapat meletus menjadi persoalan besar, yakni terjadinya konflik di antara sesama muslim, meskipun bentuk konfliknya terselubung bukan konflik kekerasan fisik

Memang hukum Islam sebagaimana tertera dalam Al-Qur'an dan AsSunnah menyebutkan adanya larangan seni dalam Islam, seperti melarang melukis makhluk hidup. Akibatnya, dalam sejarah Islam amat langka ditemukan seniman yang membuat patung dan gambar manusia. Namun demikian, tampaknya orang Islam tetap mengukuhi seni gambar meskipun harus dilakukan dengan cara menstilisasi gambar secara abstrak, dan hal ini dapat dilihat pada seni kaligrafi dan arsitektur yang yang terpahat di dalam masjid-masjid dan mushab-mushab $\mathrm{Al}$ Qur'an di Timur Tengah, yang kemudian menjadi tumbuh subur berkembang ke seluruh dunia. Melihat tumbuh suburnya seni Islam itu, orang muslim membuka kembali lembaran-lembaran Al-Qur'an dan As-Sunnah, yang didapat bahwa ternyata keduanya ditemukan adanya pesan-pesan yang berasal dari dalil-dalil dan nash-nash yang membolehkan dan melarang seni dalam Islam.

Para intelektual Islam juga mengkaji nash-nash dan dalil-dalil, baik yang terdapat dalam Al-Qur'an maupun As-Sunnah, bahwa setiap nash itu membicarakan sebuah pesan yang amat kontekstual dengan situasi ketika Nabi menghadapi berbagai persoalan. Sebagai contoh, ada nash yang turun ke bumi, isinya melarang orang membuat syair. Hal ini secara krusial ditujukan agar orang tidak pergi ke tempat-tempat yang dihuni setan, seperti gua-gua dan puncakpuncak gunung, mengingat ketika itu banyak orang Arab suka pergi ke gua-gua dan puncak-puncak gunung untuk membuat syair. Dalam artian membuat syair itu identik dengan pemujaan setan. Dampaknya ketika itu Islam melarang orang membuat syair, karena dilandasi anggapan bahwa membuat syair ada kaitannya dengan kehidupan setan di tempat-tempat, seperti gua-gua dan puncak-puncak gunung. Turunnya nash untuk melarang orang membuat syair, sempat memunculkan protes para sahabat yang juga gemar membuat syair, yang mengatakan: "Lho pekerjaan kami kan membuat syair. Jika telah diturunkan ayat yang berisi melarang membuat syair, berarti pekerjaan kami habis, terus kami akan ke mana?" Setelah terjadi protes ini, turun ayat berikutnya yang memperbolehkan orang membuat syair.

Di dalam nash yang lain, diperintahkan untuk membaca Al-Quran dengan jelas (tartil) serta lagu yang bagus. Di sini terdapat penafsiran bahwa membaca AlQur'an itu harus disertai lagu yang bagus. Lagu yang bagus merupakan bagian dari seni musik pada umumnya. Elemen-elemen di dalam seni musik terdiri dari melodi, ritme, dan harmoni. Melodi adalah bentuk lagu yang dibunyikan. Ritme adalah irama dan tempo yang digunakan untuk mengukur panjang-pendek, cepatlambat, dan akselerasi melodi. Harmoni adalah keseimbangan dalam mengekspresikan melodi berdasarkan volume, keras-lirih, cepat-lambat, dan kelembutan suara. Ketiga elemen tersebut dalam seni musik adalah pokok, dan tidak dapat ditinggalkan salah satunya. Bayangkan, jika salah satu elemen itu ditinggalkan, atau bahkan membaca Al-Qur'an tidak memakai melodi, tentu amat hambar. Unsur musikal (seni musik) ternyata amat penting, dan juga diperhatikan dalam membaca ayat-ayat Al-Qur'an. Dengan demikian hadirnya unsur seni dalam membaca Al-Qur'an adalah suatu keniscayaan.

Dalam suatu riwayat, Nabi Muhammad SAW sendiri pernah memerintahkan kepada seorang sahabat, agar ketika mempunyai hajat perhelatan perkawinan (punya kerja mantu) untuk dirayakan dengan kesenian. Dari penjelasan ini kita dapat memandang bahwa dalam Al-Qur'an dan As-Sunnah terdapat nash-nash yang membolehkan hadirnya seni dalam agama Islam. 
Akibatnya persepsi pro dan kontra masyarakat Islam terhadap kesenian tidak dapat dihindarkan hingga sekarang, baik pada tingkat kelompok maupun individual muslim. Al-Qur'an dan As-Sunnah memuat ayat-ayat yang melarang dan juga ada yang membolehkan kehadiran seni dalam Islam, dengan segala alasan dan kontekstualitas pada zamannya (Al Bagdadi, 1991: 27-38). Dengan demikian, seolah-olah hukum Islam itu meninggalkan kesan adanya pro dan kontra persepsi Islam terhadap kesenian. Padahal, seharusnya setiap orang Islam harus mampu menafsirkan, kapan seni itu dianggap haram dan kapan seni itu dianggap halal. Di samping itu, Al-Qur'an dan As-Sunnah hanyalah teks yang seharusnya diupayakan untuk diinterpretasikan sesuai dengan tempat-geografis, waktu-zaman, dan kondisi manusia sebagai pengguna kitab suci tersebut.

Yang lebih genting lagi, pro dan kontra ini juga merambah dalam percaturan intelektual kaum muslim. Ketika mereka menulis buku dalam rangka mengkaji fatwa tentang haram-halal kesenian, dengan kapasitas dan otoritasnya masing-masing, ternyata ada yang mengharamkan kesenian dengan berbagai argumentasinya, dan ada pula yang menghalalkan kesenian dengan mengajukan berbagai alasan yang bersifat positif. Dalam buku Figh, Musik, dan Lagu (AlQardlawy, 2003) disebutkan 57 orang ulama yang telah menulis untuk memberikan fatwa diperbolehkannya musik dalam kehidupan umat Islam, sebagai bantahan terhadap para ulama yang mengharamkan musik dan lagu. Hanya saja yang menjadi keprihatinan penulis adalah bila fatwa-fatwa untuk menghalalkan dan mengharamkan kesenian itu hanya dilandasi perasaan suka atau tidak suka (like/dislike) terhadap kesenian. Bagaimanapun seorang manusia itu pasti mempunyai perasaan memihak pada sesuatu yang disenangi. Seorang Muslim itu memberi persepsi haram atau halal terhadap kesenian tentu tergantung orangnya, bisa dipengaruhi daya terbang intelektual seseorang, atau menurut Muslim Abdurrahman (2003) bisa tergantung dari etnisitas dan kelas sosial yang melatarbelakangi kehidupannya.

\section{SENI DAN DUNIA ISLAM}

Bagi umat Islam khususnya para pendakwah yang berpandangan menghalalkan kesenian dalam kehidupan beragama, tentu tidak mendapati persoalan. Mereka biasanya dapat hidup berdampingan secara harmonis dengan masyarakat yang masih kental tradisinya, seperti dijumpai dalam kehidupan masyarakat pedesaan. Akan tetapi, bagi para pendakwah yang berpandangan kesenian haram, tentu akan menghadapi berbagai dilema. Tidak menutup kemungkinan akan terjadi perlawanan dan konfrontasi masyarakat dengan para pendakwah. Deliar Noer (1996) menyatakan bahwa ketika penyebaran pembaharuan Islam dilaksanakan di daerah Minangkabau, Sumatra Barat pertama kali mendapat reaksi dari kalangan tradisi. Dalam perspektif Peter L Berger (1992) menyebutkan kemungkinan-kemungkinan terjadinya konfrontasi antara agama dan tradisi selalu ada. Hal ini disebabkan Islam sebagai agama merupakan tradisi besar (high tradition) yang akan selalu melakukan penetrasi (perembesan) menembus batas dalam wilayah tradisi kecil (small tradition) yang dimiliki masyarakat pedesaan yang kaya dengan kesenian tradisonal. Sebagai agama dakwah, Islam akan selalu menyiarkan ajarannya ke berbagai ruang dan dimensi sosial, termasuk menembus tradisi-tradisi masyarakat yang ada. Perembesan Islam ke dalam tradisi membuahkan hubungan ikat-mengikat keduanya, baik bersifat interelatif, kontestantif, maupun konfliktual.

Meskipun kadang-kadang terjadi konflik dengan masyarakat, Islam dengan segala aspek globalitasnya mampu menyebar ke berbagai belahan dunia. Hal itulah yang telah terbukti dilihat oleh para pejalan/pengembara atas nama antropolog melalui hasil penemuannya berupa instrumen musik rebana atau terbang di dunia Islam. Hasil penemuan itu mewujudkan bahwa berbagai daerah di belahan bumi ini bergaung bunyi instrumen rebana dan lagu-lagu pujian untuk Allah SWT dan Nabi Muhammad SAW. Tentu saja para antropolog tidak usah berpikir lama, bahwa daerah yang dirambah tersebut dihuni oleh orang muslim. Instrumen rebana dapat dijumpai pada perangkat-perangkat musik Islam di seluruh dunia, terutama di negara-negara yang warga penduduknya memeluk agama Islam baik sebagai mayoritas maupun minoritas, mulai dari wilayah Maghrib, Afrika Tengah, Masriq, Turki, Iran dan Asia Tengah, India dan Asia Selatan, serta Asia Tenggara (Al Faruqi, 1986). Bentuk instrumennya sama, tetapi namanya berbeda, yakni: duff (Arab), nahas (Sudan), naqqarah (Kurdistan), naggara (Myanmar), kompang (Malaysia), dan di Indonesia juga beragam namanya, seperti rapai (Aceh), rebana (Riau), indhung (Jawa Barat), terbang (Jawa Tengah), dan trebang (Jawa Timur).

Telah menjadi fakta sejarah, bahwa penyebaran seni pertunjukan tradisi Islam di Indonesia begitu meluas. Hampir setiap etnis ataupun suku bangsa memiliki tradisi seni pertunjukan Islam. Sesunguhnya dapat dipertanyakan, mengapa seni Islam dapat berkembang meluas? Karena seni Islam mencerminkan realitas-realitas kehidupan yang bersumber pada Al-Qur'an serta sikap dan perilaku diri Nabi Muhammad SAW sebagai tauladan bagi seluruh umat manusia. Setiap ekspresinya, seni Islam mengumandangkan zikirullah (ingat kepada Allah), karena syair-syairnya banyak bermuara untuk kontemplasi asma-asma Tuhan, dan ini membuat kerinduan hati para penikmat yang amat dalam. Syair-syair lain khusus berkonsentrasi pada aspek kognitif, afektif, dan psikomotorik yang tercermin pada diri Nabi Muhammad SAW. Pikiran, sikap, dan prilaku Nabi SAW yang dituangkan dalam bentuk lagu-lagu dan tembang-tembang tradisi Islam merupakan aspek idealisme tersendiri. Dengan demikian dapat disimpulkan bahwa seni Islam merupakan ekspresi estetik yang bersumber pada wahyu Illahi. 
Wahyu Illahi merupakan pusat dan mata air yang mengalir ke seni Islam. Dari sinilah, seni Islam melarutkan realitas-realitas batin ilham Islam dalam sebuah dunia bentuk, dan keluarnya ilham ini menuntun manusia masuk ke ruang batin wahyu Illahi. Oleh karena itu, Nasr (1994) melihat seni Islam sebagai buah dari spiritualitas Islam. Alasannya, seni Islam merefleksikan kandungan prinsip keesaan Illahi, ketergantungan seluruh keanekaragaman kepada sang pencipta, dan kesementaraan dunia serta kualitas-kualitas kehidupan yang amat positif.

Tentu saja pesan-pesan yang cukup lengkap itu dikumandangkan dalam bentuk ekspresi estetis atau pentas seni (Cooke, 2014: 94), dan ini sama saja dengan ketika seorang pendakwah melakukan syiar Islam. Hanya saja bedanya kalau pendakwah biasanya melalui ekspresi lisan, misalnya khotbah dan ceramah. Akan tetapi, dalam seni Islam, dakwah dilaksanakan dalam bentuk ekspresi estetik. Meminjam istilah Sidi Gazalba (1977: 56), dakwah Islam dilaksanakan melalui saluran estetis. Dalam perspektif Islam, dakwah itu yang penting dilakukan, terserah hasilnya akan diterima atau ditolak tergantung audiennya.

\section{FENOMENA INSTITUSI SOSIAL KEAGAMAAN}

Munculnya kelompok-kelompok dan institusi sosial keagamaan di Indonesia seperti Muhammadiyah, Nahdatul Ulama, Mujahidin, LDII, Islam Liberal, dan Hizbut Tahrir mewarnai parmasalahan pandangan Islam terhadap kesenian. Sebagai contoh institusi Muhammadiyah memiliki visi dan misi mengembalikan ajaran Islam dengan mengedepankan doktrin-doktrin dalam AlQur'an dan As-Sunnah, dan memberantas syirik, tahayul, bid'ah, dan churofat. Kesenian khusunya yang tradisional dalam hal ini termasuk bid'ah, dan oleh karena seringnya difungsikan untuk acara-acara ritual dianggap churofat. Dengan demikian warga Muhammadyah banyak yang memberikan persepsi bahwa kesenian itu haram. Namun di balik itu, realitas di lapangan menyebutkan banyaknya para dai atau mubaligh Muhammadiyah yang ikut andil sebagai pemain slawatan. Implikasinya bahwa warga Muhammadiyah dalam hubungan ini memberikan persepsi haram dan juga halal terhadap kesenian.

Dalam hal hadis yang menyebutkan adanya larangan melukis manusia, binatang, dan makhluk hidup, pada tahun 1969 pernah terjadi polemik yang mempersoalkan lukisan K.H. Ahmad Dahlan (pendiri Muhammadiyah) yang dipasang di dinding sekolah-sekolah dilarang oleh Pusat Pimpinan (PP) Muhammadiyah, dengan alasan agama Islam melarang untuk melukis makhluk hidup. Gambar tersebut menimbulkan persepsi dan kontroversi masyarakat berkepanjangan. Hingga sekarang, kontroversi tersebut belum terselesaikan.

Kemungkinan berdasarkan platform Muhammadiyah pada tahun itu, para anggotanya banyak yang tidak mengakses seni tradisional, meskipun kebudayaan seni tradisional waktu itu masih mengental dengan masyarakat, terutama masyarakat Jawa. Dikatakan tidak mengakses, karena banyak orang-orang Muhammadiyah yang tidak mempunyai perangkat kesenian tradisional. Jika mempunyai perhelatan, seperti perkawinan dan khitanan, warga Muhammadiyah tidak menggunakan seni tradisional sebagai media hiburan dan ritual. Meskipun misi Muhammadiyah tetap kukuh memberantas bid'ah, namun realitas sosialnya tidak demikian. Banyak mubaligh (pendakwah) Muhammadiyah yang mengembangkan langkah-langkah dan aktivitas dakwahnya dikombinasi dengan menampilkan seni tradisional. Di Yogyakarta, Surakarta, dan sekitanya sebagai daerah basis Muhammadiyah, para mubaligh yang berasal dari kalangan guru Muhammadiyah dan Departemen Agama mengembangkan dakwahnya dengan menampilkan kesenian (Anas, 2003: 219), antara lain slawatan Jawa, wayang purwa, yang mendapat respon positif dari masyarakat Jawa.

Geertz juga mencatat sikap dan persepsi orang-orang Muhammadiyah di Mojokuto terhadap seni tradisional. Salah satu informan Geertz (1989: 211) mengungkapkan bahwa menonton kesenian apapun bentuknya sama saja membuang-buang waktu dan menganggap tidak ada manfaatnya. Tidak hanya seni wayang saja, tetapi bentuk kesenian yang lain juga tidak disenangi, termasuk seni membaca doa panjang yang dilakukan oleh orang-orang Islam ortodoks dianggap oleh kelompok Muhammadiyah sebagai sesuatu yang mubazir atau tidak ada gunanya. Berdasarkan sikap ini, akibatnya bentuk-bentuk kesenian amat langka dijumpai di kalangan Muhammadiyah (Geertz, 1989: 211). Pernyataan Geertz ini bisa disinyalir bahwa Muhammadiyah amat gigih menegakkan misi institusinya untuk memberantas bid'ah dan memurnikan ajaran Islam berdasarkan kitab suci Al Qur'an dan hadist Nabi Muhammad SAW. Namun demikian, dari pernyataan itu juga mengindikasikan bahwa langkanya orang Muhammadiyah yang mengakses kesenian, berarti juga ada di antara anggota Muhammadiyah yang masih menggunakan kesenian untuk kepentingan tertentu. Hanya saja Geertz tidak mengungkap orang-orang Muhammadiyah yang memanfaatkan seni tradisional, dan menanyakan lebih lanjut bagaimana sikap orang Muhammadiyah setelah memanfaatkan kesenian itu.

Demikian pula Nakamura (1983) menyebutkan seni kethoprak berlatar kerakyatan dinikmati wong cilik. Dunia kethoprak merupakan dunia yang liar dan tidak tertib, dengan menggunakan medium bahasa Jawa umum. Cerita kethoprak diambil dari peristiwa dalam sejarah rakyat, misalnya jaman Majapahit, Mataram, Cina, dan India. Dua jenis seni pertunjukan yang berlangsung di Kota Gede mendapat antusias penonton, terutama mereka yang berusia muda sekitar belasan dan duapuluhan tahun. Antara penonton pria dan wanita bercampur baur tanpa memandang kategori jenis kelamin dan batas-batas kesusilaan. Seorang anggota Muhammadiyah yang sudah tua memberi persepsi terhadap pertunjukan kethoprak, bahwa menonton pertunjukan itu membuat perasaan menjadi malas, 
100 imaji, Vol. 12, No. 2, Agustus 2014 : 91 - 102

dan melemahkan keinginan untuk bekerja keras. Menonton kethoprak sama saja dengan perbuatan yang tidak disadari untuk berpikir mana yang baik dan mana yang buruk. Dengan kata lain, bahwa penjelasan ini memberikan gambaran pemikiran Muhammadiyah di Kota Gede, bahwa melihat kesenian (wayang dan kethorak) semalam suntuk merupakan bentuk pelemahan hawa nafsu.

Informasi yang secara khusus melaporkan hubungan seni dan Muhammadiyah adalah Purifikasi dan Reproduksi Budaya di Pantai Utara Jawa: Muhammadiyah dan Seni Lokal (Chamim, 2003). Informasi ini melihat dialektika agama dan pluralitas budaya lokal di daerah Lamongan, Jawa Timur. Hasil studi tersebut mengungkapkan formalisasi syariah dalam gerakan Muhammadiyah berpengaruh signifikan bagi persentuhan Muhammadiyah dengan kesenian, terutama kesenian lokal. Hampir setiap tradisi lokal--santri maupun kejawen-melahirkan ekspresi kesenian. Berbagai tradisi itu diidentifikasi oleh Muhammadiyah mengandung muatan yang berakar dari tradisi pra-Islam, sehingga dianggap syirik, tahayul, bid'ah, dan khurafat. Ekspresi kesenian apapun yang berkaitan dengan tradisi lokal meskipun dikemas dengan identitas santri seperti syi'iran dan slawatan, tetap dianggap bertentangan dengan syariah Islam, karena para mubaligh Muhammadiyah memandangnya sebagai peristiwa bid'ah dan khurafat serta hal tersebut tidak pernah dilakukan pada masa Nabi Muhammad. Namun syariah Islam yang terkesan keras itu harus ditebus dengan biaya kultural. Sebagai akibatnya ventilasi estetika dan kesenian di lingkungan Muhammadiyah tertutup. Muhammadiyah terkesan kering dan sangat formalis, karena kurang mengapresiasi terhadap khazanah lokal yang tumbuh dan berkembang dengan baik. Formalisasi syariah itu sendiri lahir sebagai akibat dominasi ahli syariah, terutama oleh para pimpinan dan mubaligh Muhammadiyah. Di samping itu, banyak kesenian lokal dipandang memilik implikasi moral yang negatif (demoralisasi) bagi masyarakat luas akibat visualisasi kesenian lokal yang cenderung mengumbar nafsu dan aurat.

Sementara itu, gagasan tentang kemajuan (the idea of progress) tercermin dalam bentuk pengembangan di lembaga pendidikan Muhammadiyah dan Lembaga Seni Budaya Pimpinan Daerah Muhammadiyah Lamongan. Oleh karena Muhammadiyah mengacu pada gagasan kemajuan tersebut, maka akomodas kesenian yang dikembangkan adalah jenis kesenian yang dianggap modern, seperti drum-band, teater, dan paduan suara (Chamim, 2003: 130). Terlepas dari hubungan seni dan struktur Muhammadiyah di Lamongan, masih terdapat realitas kesenian yang berjalan sendiri di kalangan grass-root warga Muhammadiyah.

Sementara itu lembaga Muhammadiyah sendiri akhir-akhir ini jug mendapat berbagai kritik, baik berasal dari warga Muhammadiyah sendiri maupun pihak luar (Hamid, 2000: 76), sehubungan dengan posisinya sebagai lembaga gerakan pemurnian Islam di Indonesia dalam memberikan persepsi dan respon atas
Seni Tradisi di Indonesia dan Fenomena Haram-Halal (Sutiyono)

kehidupan seni tradisional. Mereka mengkritik Muhammadiyah dengan berbagai tuduhan, antara lain (1) Lembaga Muhammadiyah hingga sekarang jauh dari seni tradisional dan anti budaya lokal (Abdurahman, 2003: 8), atau menurut istilah Kuntowijoyo merupakan penyakit kultural yang alergi terhadap tradisi budaya (Hamid, 2000: 77), (2) Muhammadiyah dituduh oleh anggotanya, bertanggung jawab terhadap punahnya seni tardisional. Tuduhan ini masih terjadi kontroversi, dan perlu dibuktikan di lapangan, (3) Agama Islam dianggap menjadi buldozer seni dan budaya tradisional, (4) Banyak anggota Muhammadiyah yang lari ke NU, karena merasa jiwa seninya tidak tersalurkan di Muhammadiyah. Selain itu, dalam pandangan penyair dari Madura, Zawawi Imron (2000), Muhammadiyah dianggap sebagai lahan tandus tumbuhnya kesenian.

Sekarang ini, meskipun visi dakwah Muhammadiyah berubah, yaitu menetapkan konsep "Dakwah Kultural Muhammadiyah" dengan mencanangkan strategi apresiasi kesenian, kenyataannya di dalam tubuh Muhammadiyah masih banyak terdapat pro dan kontra dalam memberikan persepsi terhadap kesenian. Sebagai bukti, para dai Muhammadiyah ada yang setuju dan ada pula yang tidak setuju terhadap konsep "Dakwah Kultural Muhammadiyah", dan hal ini mereka tulis dalam kolom surat pembaca pada terbitan dua-mingguan majalah Suara Muhammadiyah.

\section{KESIMPULAN}

Dari beberapa paparan di atas dapat disimpulkan bahwa genre kesenian Islami, termasuk di antaranya slawatan masih hidup di masyarakat terutama di pedesaan sampai sekarang. Secara positif kesenian Islami mampu membentuk ikatan silaturahmi, bahkan ada di antaranya yang dapat merubah akhlak seseorang yang tadinya tidak agamis menjadi penganut Islam taat. Akan tetapi, di balik itu genre kesenian Islami masih menghadapi justifikasi dari kelompok orang Islam sendiri yang memberikan persepsi atas kesenian tersebut, yakni ada yang menganggap haram dan ada pula yang menganggap halal.

\section{DAFTAR PUSTAKA}

Abdurrahman, Moeslim (ed.). 2003. Muhammadiyah Sebagai Tenda Kultural. Jakarta: Ideo Press.

Al-Bagdadi, Abdurrahman. 1991. Seni dalam Pandangan Islam: Seni Vokal, Musik, dan Tari. Jakarta: Gema Insani Press.

Al-Qardlawy, Yusuf. 2003. Fiqih, Musik, dan Lagu: Perspektif Al-Qur'an dan AsSunnah. Terjemahan dari Figh Al-Ghina wa al Musiqy fi Dhau-I Al-Quran waAs-Sunnah Bandung: Mujahid.

Anas, Ahmad. 2003. Menguak Pengalaman Sufistik: Pengalaman Keagamaan Jamaah Maulid al-Diba Girikusumo. Yogyakarta: Pustaka Pelajar. 
102 imasi, Vol. 12, No. 2, Agustus $2014: 91$ - 102

Berger, Peter L.. 1994. Langit Suci: Agama Sebagai Realitas Sosial. Terjemahan dari The Cacred Canopy. Jakarta: LP3ES.

Berger, Peter L. dan Thomas Luckmann. 1994. Tafsir Sosial atas Kenyataan. Terjemahan dari The Social Construction of Reality: A Treatise in the Sociology of Knowledge. Jakarta: LP3ES.

Cooke, Peter. 2014. "Defending Kakraba, Promoting Intercultural Curiosty". Ethnomusicology Forum, Vol. 23, No. 1, pp. 94-109.

Hamid, Edy Suandi (et. al.). 2000. Rekonstruksi Gerakan Muhammadiyah pada Era Multiperadaban. Yogyakarta: UII Press.

Chamim, Asyukri Ibn (et. al.). 2003. Purifikasi dan Reproduksi Budaya Di Pantai Utara Jawa. Surakarta: Pusat Studi Budaya dan Perubahan Sosial, Universitas Muhammadiyah Surakarta.

Gazalba, Sidi. 1977. Pandangan Islam terhadap Kesenian. Jakarta: Bulan Bintang.

Irfani, Adistya Iqbal (et. al.). 2013. "Toleransi antar Penganut Nahdatul Ulama, Muhammadiyah, dan Kristen Jawa di Batang”. Jurnal Komunitas, Vol. 5 No. 1, pp. 1-13.

Nakamura, Mitsuo. 1983. Bulan Sabit Muncul Dari Balik Pohon Beringin: Studi tentang Pergerakan Muhammadiyah di Kotagede, Yogyakarta. Yogyakarta: Gadjah Mada University Press.

Nasr, Seyyed Hossein. 1994. Spiritualitas dan Seni Islam. Terjemahan dari Islamic Art and Spirituality. Bandung: Mizan.

Noer, Deliar. 1996. Gerakan Moderen Islam di Indonesia 1900-1942. Jakarta: LP3ES.

Sutiyono. 1999. "Larasmadya: Ekspresi Budaya Musik Tradisi Jawa-Islam di Sleman, Yogyakarta". Tesis S-2 Pasca Sarjana Universitas Gadjah Mada, Yogyakarta. 